\title{
EVALUACIÓN SENSORIAL Y FÍSICOQUÍMICA DE PANES CON SUSTITUCIÓN PARCIAL DE LA HARINA DE TRIGO (Triticum aestivum) POR HARINAS DE MAÍZ (Zea mays) Y PAPA (Solanum tuberosum)
}

\author{
Physicochemical and sensory evaluation of reinforce bread with partial replacement of wheat \\ flour (Triticum aestivum) by corn (Zea mays) and potato (Solanum tuberosum) flours
}

Antonio Obregón ${ }^{1}$, Eliana Contreras ${ }^{2}$, Ana María Muñoz ${ }^{2}$, Rita Ayquipa ${ }^{3}$, Wendy Fernández ${ }^{3}$

${ }^{1}$ Centro Latinoamericano de Enseñanza e Investigación en Bacteriología Alimentaria - CLEIBA. ${ }^{2}$ Instituto de Investigación en Química Biológica, Microbiología y Biotecnología, “Marco Antonio Garrido Malo”. ²Escuela Académica de Ciencia de los Alimentos. Facultad de Farmacia y Bioquímica, Universidad Nacional Mayor de San Marcos

\section{RESUMEN}

Se realizó la evaluación sensorial y se estudió la composición química y valor nutricional de pan fortificado con hierro, con sustitución parcial de harina de trigo por harinas de papa y maíz en un 10\%, obteniendo un pan de textura suave, agradable y de muy buena aceptabilidad, destinado a niños en edad escolar. El pan elaborado presenta contenidos de proteína 13,10\%; extracto etéreo 9,80\% y carbohidratos 50,32\%, con un valor energético de 341,88 kcal/10o g; aporta 10,13 mg/100 g de hierro, satisfaciendo la cantidad diaria recomendada de hierro para niños en edad escolar.

Palabras clave: Solanum tuberosum, Zea mays, fortificación del pan, sustitución parcial de harinas.

\section{SUMMARY}

It was realized the sensorial evaluation_and were studied the chemical composition and nutritional value of ironfortified bread, with partial replacement of $10 \%$ of its wheat flour content by potato and corn flour, obtaining a bread with soft texture, palatable and very good acceptability for children of school age. The elaborated bread contains protein 13,10\%; fat $9,80 \%$ and carbohydrates $50,32 \%$, with an energy value of $341,88 \mathrm{kcal} / 100 \mathrm{~g}$ and an iron content $10,13 \mathrm{mg} / 100 \mathrm{~g}$, that satisfies the recommended dietary allowance of iron for schoolchildren.

Keywords: Solanum tuberosum, Zea mays, fortification of bread, partial flour substitution.

\section{INTRODUCCIÓN}

A ctualmente, se vienen desarrollando diferentes productos alimenticios dirigidos a niños, que se caracterizan principalmente por ser productos fortificados y nutritivos, dentro de los cuales podemos encontrar productos de panificación elaborados por sustitución de harina de trigo por harina de tubérculos, cereales o granos nativos, que aumentan su valor nutricional, haciéndolos ideales para los niños, más aún si se tiene en cuenta que forman parte del alimento básico en el desayuno. Es necesario considerar, en el desarrollo de un producto, no sólo el valor nutricional, sino también parámetros de inocuidad, calidad y sobre todo que tenga un buen nivel de aceptabilidad para su consumo, ya que de esta manera los niños podrán consumir de forma integral el producto, aprovechando sus características nutricionales y organolépticas.

Además de la evaluación fisicoquímica, un punto importante en el desarrollo de nuevos productos alimenticios, es la evaluación sensorial, ya que puede condicionar el éxito o el fracaso de los nuevos productos para su consumo en la población a la que va dirigido. En este caso tenemos como público objetivo a los niños, que son un grupo muy especial, por ser más exigentes en cuanto a sabor, aroma y textura lo que ingieren.

El pan es uno de los principales alimentos de la dieta diaria, cuyo consumo se ve afectado por el alto costo de la principal materia prima que es la harina de trigo, lo que conduce a buscar nuevas alternativas para su elaboración.

Enel Perú secultivan productos muysemejantesal trigo que bien pueden ser empleados — con la correspondiente observación científica- para sustituir la harina que se obtiene de él, tales como maíz, yuca, papa, camote, entre otros, los cuales no poseen las mismas características panificables del trigo, pero pueden utilizarse en diferentes niveles de sustitución para la elaboración de pan ${ }^{(1)}$.

Las distintas formulaciones desarrolladas de pan, que tengan aceptabilidad y preferencia entre los consumidores, serán los productos más exitosos y completos; por tal motivo, es necesario de realizar 
estudios de evaluación sensorial para determinar la efectividad de su consumo en la población objetivo. En ese sentido se desarrolló la presente investigación cuyo objetivo fue evaluar la incidencia de la incorporación de harinas de papa y de maíz como sustituto parcial del trigo en el proceso de elaboración de un pan fortificado y determinar su aceptabilidad de consumo en niños en edad escolar.

\section{MATERIALES Y MÉTODOS}

\section{Insumos}

Como insumos se utilizaron harina de papa, harina de maíz, harina de trigo, gluten, manteca, azúcar, sal, saborizante anís y mejorador de masa. Se utilizó sulfato ferroso como fuente de hierro, en una cantidad de $5 \mathrm{mg} /$ ración.

\section{Fórmulas referenciales}

Se probaron 04 fórmulas referenciales, las cuales se detallan en la tabla 1.

\section{Proceso de elaboración del pan}

El proceso de elaboración del pan fue realizado mediante el método directo, por el cual una vez pesados los ingredientes se combinan en una mezcladora. Luego la masa se corta, se bolea y se deja fermentar por un período de 1,5 horas aproximadamente, para posteriormente ser horneada a $150^{\circ} \mathrm{C}$ por alrededor de 15 a 18 minutos. Finalmente, los panes son enfriados antes de ser sometidos a las pruebas respectivas ${ }^{(2)}$.

\section{Evaluación sensorial}

\section{Adriestamiento}

Para seleccionar la mejor formulación se contó con jueces semi adriestados, los cuales fueron sometidos a una serie de pruebas con el objetivo de capacitarlos en identificar la muestra que presenta mayor aceptación y preferencia ${ }^{(3)}$.

\section{Prueba de ordenamiento}

Los panes elaborados con las cuatro fórmulas, fueron sometidos a una Prueba de Ordenamiento siendo evaluados por jueces semi adriestados a quienes se pidió que ordenen las muestras de mayor a menor aceptación, de acuerdo al atributo evaluado, con el objetivo de seleccionar la muestra con mayor preferencia. Los resultados fueron evaluados mediante la prueba estadística no paramétrica de Friedman a un nivel del $5 \%$ de significancia ${ }^{(3)}$.

\section{Prueba de Aceptabilidad (Escala Hedónica)}

La muestra o muestras que presentaron los mayores calificativos, en la prueba de ordenamiento, fueron evaluados mediante una escala hedónica de tres puntos, con el fin de determinar la muestra con mayor grado de aceptabilidad. La prueba se llevó a cabo en una institución educativa con escolares de 6 a 12 años deedad, a los cuales se pidió que evaluaran la aceptabilidad del producto mediante la siguiente escala de calificación:

$\begin{array}{cl}\text { Escala } & \text { Percepción sensorial } \\ 1 & \text { NO ME GUSTA } \\ 2 & \text { NO ME GUSTA, NI ME DISGUSTA } \\ 3 & \text { ME GUSTA }\end{array}$

Los resultados fueron evaluados estadísticamente mediante la prueba no paramétrica de Friedman, a un nivel de $5 \%$ de significancia ${ }^{(3)}$.

\section{Evaluación físico-química, bromatológica y organoléptica}

El producto final que presentó los mayores calificativos en la escala hedónica fue caracterizado fisicoquímicamente mediante la determinación de contenido de agua, proteínas totales, extracto etéreo, cenizas y fibra, utilizando los métodos de la AOAC ${ }^{(4)}$. El factor utilizado para calcular la proteína fue de 6,25. Los carbohidratos fueron obtenidos por diferencia, de los demás componentes. El valor calórico total, así como el proveniente de la proteína, grasa y carbohidratos, se determinaron siguiendo lo recomendado por la AOAC (4). Asimismo, la muestra con mayor calificativo fue evaluada organolépticamente ${ }^{(3)}$.

\section{RESULTADOS}

En los cuadros siguientes las tablas 2, 3, 4, 5 y 6 se presentan los resultados obtenidos. 


\section{DISCUSIÓN}

En la tabla 1 se observa que las formulaciones tres y cuatro fueron ordenadas por los jueces como las muestras con mayor preferencia, , mientras en la tabla

Tabla 2. Resultados de la Prueba de Ordenamiento.

\begin{tabular}{lcccc}
\hline \multicolumn{1}{c}{$\begin{array}{c}\text { Atributo } \\
\text { sensorial }\end{array}$} & \multicolumn{4}{c}{ Calificación promedio } \\
\cline { 2 - 5 } & Fórmula 1 & Fórmula 2 & Fórmula 3 & Fórmula 4 \\
\hline Sabor & 3,00 & 3,25 & 2,25 & 1,50 \\
Apariencia general & 3,88 & 2,75 & 1,75 & 1,63 \\
Aroma & 3,25 & 3,25 & 1,75 & 1,75 \\
Color & 3,25 & 2,63 & 1,88 & 2,25 \\
\multicolumn{1}{c}{ Total } & 3,35 & 2,97 & 1,91 & 1,78 \\
\hline
\end{tabular}

Tabla 3. Resultados de la Prueba de comparación entre tratamientos de Friedman.

\begin{tabular}{ccccc}
\hline \multirow{2}{*}{$\begin{array}{c}\text { Comparación } \\
\text { entre } \\
\text { tratamientos }\end{array}$} & \multicolumn{4}{c}{ Diferencia Estadística de Friedman } \\
\cline { 2 - 5 } & Sabor & $\begin{array}{c}\text { Apariencia } \\
\text { general }\end{array}$ & Aroma & Color \\
\hline T1-T2 & 2 & $9^{*}$ & 0 & $7^{*}$ \\
T1-T3 & $6^{*}$ & $17^{*}$ & $12^{*}$ & $17^{*}$ \\
T1-T4 & $12^{*}$ & $18^{*}$ & $12^{*}$ & $12^{*}$ \\
T2-T3 & $8^{*}$ & $8^{*}$ & $12^{*}$ & $10^{*}$ \\
T2-T4 & $14^{*}$ & $9^{*}$ & $12^{*}$ & $19^{*}$ \\
T3-T4 & $6^{*}$ & 1 & 0 & $5^{*}$ \\
\hline
\end{tabular}

${ }^{*}$ Resultado significativo a un nivel de con $5 \%$ de significancia.

Fórmula 1: T1; Fórmula 2: T2; Fórmula 3: T3; Fórmula 4: T4

Tabla 4. Resultados de la Prueba de Escala Hedónica.

\begin{tabular}{ccc}
\hline \multirow{2}{*}{ Atributo Evaluado } & \multicolumn{2}{c}{ Calificación promedio } \\
\cline { 2 - 3 } & Fórmula 3 & Fórmula 4 \\
\hline Grado de Satisfacción & 2,68 & 2,86 \\
\hline
\end{tabular}

Tabla 5. Composición físico-química y bromatológica del producto final.

\begin{tabular}{lcc} 
& $\begin{array}{c}\text { Fórmula } \\
\%\end{array}$ & $\begin{array}{c}\text { Fórmula } \\
\mathbf{\%}\end{array}$ \\
\hline Humedad & 26,36 & 25,78 \\
Proteína & 10,88 & 13,10 \\
Extracto etéreo & 10,13 & 9,80 \\
Cenizas & 0,98 & 1,00 \\
Fibra cruda & 4,37 & 1,88 \\
Carbohidratos & 51,65 & 50,32 \\
Acidez* & 0,06 & 0,09 \\
Hierro** & 8,47 & 10,13 \\
Bromato de potasio & Ausencia & Ausencia \\
Energía total*** & 341,29 & 341,88 \\
Energía prov. de la proteína & 12,75 & 15,33 \\
Energía prov. de la grasa & 26,71 & 25,80 \\
Energía prov. de los carbohidratos & 60,54 & 58,87 \\
\hline
\end{tabular}

Tabla 6. Evaluación organoléptica del pan a base de harinas de maíz y de papa.

\begin{tabular}{cc}
\hline Evaluación organoléptica & Descripción \\
\hline Aspecto & Pan de forma redonda \\
Color & Exterior: marrón Interior: Crema \\
Olor & A pan y anís \\
Sabor & A pan y anís, ligeramente dulce \\
Textura & Suave \\
\hline
\end{tabular}

2, se muestran los resultados estadísticos de la prueba de comparación entre tratamientos. Es preciso señalar que estas formulaciones tuvieron un mayor porcentaje de sustitución de harina de maíz por harina de trigo.

El Laboratorio de Panificación de la UNALM (5), encontró que es posible sustituir, como máximo, hasta un 30\% dela harina de trigo porpapa precocida sin afectar las características organolépticas del pan. Asimismo, Fernández (6), sustituyó hasta un $5 \%$ de la harina de trigo con harina de papa, y posteriormente, Escobedo ${ }^{(7)}$, utilizó $20 \%$ de harina de papa precocida en la producción del pan.

En la tabla 4 se muestran los resultados de la evaluación sensorial del grado de aceptabilidad, por parte de escolares, mediante la escala hedónica, evidenciándose que los panes elaborados con la formula 4, obtuvieron mayores calificativos comparados con los de la fórmula tres. Sin embargo, la prueba de Friedman resultó no significativa a un nivel de $5 \%$ de significación, es decir, que no existieron diferencias estadísticas, en cuanto a aceptabilidad, entre estas dos fórmulas. La fórmula 4, con mayor calificativo, contenía iguales proporciones de harina de maíz y de papa, que en total, sustituyeron al 10\% de la harina de trigo.

La tabla 5 muestra la composición físicoquímica y bromatológica de las fórmulas que presentaron mayor aceptabilidad entre los escolares mediante la escala hedónica.

Los contenidos de proteína, extracto etéreo, ceniza, fibra y carbohidratos de los panes elaborados con las fórmulas 3 y 4 presentaron valores superiores a los reportados por Collazos et $a l^{(8)}$, quien estudió panes elaborados sólo con harina de trigo. Asimismo, estas formulaciones son superiores al aportar el 16\% de la energía y el 100\% del hierro requeridos diariamente para niños en edad escolar de 6 a 12 años de edad, por la FAO.

Cerón et $a l^{(1)}$, encontraron que los panes elaborados con harina de papa presentaron valores de proteína y grasa mayores que los panes elaborados sólo con harina de trigo, lo que concuerda con los resultados obtenidos en la presente investigación.

Los resultados de la evaluación organoléptica, muestran un pan de textura suave, ligeramente dulce y de aroma anís, agradable y de muy buena aceptabilidad. 


\section{CONCLUSIONES}

- La fórmula con mayor grado de aceptación, contenía iguales proporciones de harina de maíz y de papa, que en total reemplazaron al 10\% de la harina de trigo.

- El pan elaborado presenta contenidos de proteína 13,10\%; extracto etéreo 9,80\% y carbohidratos $50,32 \%$. Con un valor energético de $341,88 \mathrm{kcal} / 100$ $\mathrm{g}$, aporta 10,13 mg/10o g de hierro, satisfaciendo la cantidad diaria recomendada para niños en edad escolar.

- Los resultados confirman la posibilidad de utilizar harinas de papa y de maíz como sustituto parcial de la harina de trigo, obtenido un pan de textura suave, agradable y de muy buena aceptabilidad.

\section{REFERENCIAS BIBLIOGRÁFICAS}

1. Cerón A, Hurtado A, Osorio O, Buchely M. Estudio de la formulación de la harina de papa de la variedad parda pastusa (Solanum tuberosum), como sustituto parcial de la harina de trigo en panadería. Biotecnología en el Sector Agropecuario y Agroindustrial 2011; 9(1): 115-21.

2. Montoya J, Román P. y Maribel, G. Estudio de la incidencia de incorporación de papa de variedad superchola (Solanum tuberosum), como sustituto parcial de harina de trigo (Triticum spp), en el proceso de elaboración de pan. Facultad de Ingeniería de Ciencias Agropecuarias Y Ambientales. Universidad Técnica del Norte. IbarraEcuador, 2010.

3. Anzaldua M. La Evaluación sensorial de los alimentos teoría y práctica. Acribia. Madrid, 1994.
4. AOAC. Official Methods of Analysis of the Association of Official Analytical Chemist International. $15^{\text {th }}$ ed. Gaithersburg, Maryland, 2005.

5. Laboratorio de panificación. Universidad Nacional Agraria La Molina. Papa pan como sustituto parcial de la harina de trigo por puré de papa de la variedad canchán. Agronegocios 2008; 3(3): 23-7.

6. Fernández D. Harina de papa su almacenamiento y uso en panificación. [Tesis para optar el grado o título de Ingeniero en Industrias Alimentarias]. Facultad de Industrias Alimentarias. Universidad Nacional Agraria La Molina. Lima, 1971.

7. Escobedo A. Obtención de la harina precocida de papa a nivel de planta piloto y su caracterización. [Tesis para optar el grado o título de Ingeniero en Industrias Alimentarias]. Facultad de Industrias Alimentarias. Universidad Nacional Agraria La Molina. Lima, 1985.

8. Collazos C, White H, Viñas E, Alvistor E, Uriquieta R, Vásquez J, et al. Tablas peruanas de composición de alimentos. Ministerio de Salud, Instituto Nacional de Salud y Centro de Alimentación y Nutrición. $8^{\text {va }}$ ed. Lima, 2009.

9. Pineda B, Vásquez L. Evaluación fisicoquímica y sensorial de pan suplementado con diferentes concentraciones de harina de papa. XII Congreso Nacional de Ciencia y Tecnología de Alimentos. Guanajuato, 2010.

10. Escobar A, Varela J. Aprovechamiento de la harina de papa criolla (Solanum phureja) como sustituto parcial de la sémola de trigo en la formulación y elaboración de una pasta alimenticia tipo spaguetti. [Tesis para optar el grado o título de Ingeniero de Alimentos]. Facultad de Ingeniería de Alimentos. Universidad de La Salle. Bogotá, 2008. 